\title{
Tracking cave shape development with microseismic data
}

\author{
R Lynch Institute of Mine Seismology, Australia \\ S Meyer Institute of Mine Seismology, Australia \\ E Lötter Institute of Mine Seismology, Australia
}

J Lett Newcrest Mining Limited, Australia

\begin{abstract}
Microseismic monitoring is routinely used by block and panel caving mines worldwide to track cave shape development. The standard practice is to use the cloud of seismic event locations as a proxy for cave growth below. Careful seismic sensor array planning overcomes problems with event location reliability due to seismic-ray bending around the unknown cave. However, the aseismic gap - the (unknown) zone between actual cave back and bottom of the seismic event cloud - complicates estimation of cave geometry. More information than simple seismic event locations can be used to infer the cave shape and position.

Since seismic events slip according to the stresses acting locally at the source locations, an analysis of source mechanisms yields indications of principal stresses around the cave. These stresses are the result of the virgin stresses perturbed by the cave shape, and this yields information about the cave shape. The apparent seismic wave arrivals under the straight-ray assumption are retarded when rays bend around the cave. These anomalous travel times are used to create 'spaghetti' - 3D curved lines indicating the likely ray path followed. Analysis of these curved rays in space and time suggests where the cave is and where it is growing.

All of this indirect information is now routinely used at Cadia East mine in Australia to estimate the cave shape, helping geotechnical engineers to better manage the cave. A direct verification of the estimated cave shape with an open hole drilled to the cave back in early 2017 provided some validation of these seismic data techniques.
\end{abstract}

Keywords: cave tracking, microseismic, source mechanisms, travel times

\section{$1 \quad$ Introduction}

In caving mines, and in particularly in block and panel caving mines, there is limited control over the growth of the cave after initiation. As the cave shape and growth has both important safety and economic consequences, careful monitoring is a priority for such mines. Passive microseismic monitoring is a widely used tool for this, deployed at all of the world's major hard rock block and panel cave mines. While it is a well-developed tool (see for example Mendecki 1997), mine seismic monitoring is an actively developing field with continual improvements.

Microseismic data is routinely used at the Cadia East caving operation in New South Wales, Australia to track the progression of the caves created by mining. At this time, the PC1 cave has broken through to surface, so there is less emphasis on seismic monitoring of the cave shape. The PC2 cave is still actively developing, joined to the PC1 cave in October 2016, and is showing positive signs of cave growth over the full footprint, including surface interaction. Reliable monitoring of that cave's development is thus still required.

The current use of microseismic data for tracking cave growth tends to only utilise seismic event locations and their migration over time. Fundamentally, there is nothing wrong with this. However, it is somewhat limited and ignores some useful and rich information contained within microseismic data. This paper explores methods and techniques to extract additional information from microseismic data, improving the reliability of the method and increasing the volume in which the cave shape can be constrained. Seismic event locations are still used, but now by incorporating seismic source mechanisms and anomalous travel times, larger 
regions of the rock mass are effectively sampled. Seismic event locations provide point data at the location of the event, source mechanisms provide information on the stress field at the location of the event, relative to cave geometry, while anomalous travel times provide insight into the path between event and sensor. This paper can be considered an update to Lynch (2016).

Another method of using microseismic data to infer changes to the state of the cave is travel tomography, which has been applied to block caving mines (Westman et al. 2012; Mercier et al. 2015). These studies have shown that the application of this method can be a useful tool to see the evolution of caves over time, but have also illustrated that the method is not capable of resolving the sharp velocity contrasts associated with caving mines (with the velocity inside the cave being overestimated and the velocity outside the cave being underestimated). This 'smearing' effect that blurs the boundary between the cave and the host rock prohibits the delineation of the cave-rock boundary with spatial accuracy better than 50-100 m (depending on event and sensor coverage), greater than the current desired accuracy and requirements of operational mines.

Travel time tomography also requires a large number of seismic events with good spatial coverage of the area to be imaged. This often requires collecting data for a month or more (Mercier et al. 2015). Caving rates can vary significantly over short terms, from low rates ( $1-2 \mathrm{~m} /$ week) to high rates ( $10 \mathrm{~m} /$ day) up to extreme rates ( $>50 \mathrm{~m} /$ day). However, long-term average rates can be expected to be in the order of up to a few $\mathrm{m} /$ day (Lett et al. 2016). Therefore, during a one month period, the cave can easily be expected to grow vertically up to $50 \mathrm{~m}$. This implies that monthly tomographic images will not be sufficient and will cause further smearing and ambiguity.

\section{Caving environment}

As far as microseismic monitoring goes, the cave mining environment is very different from other underground hard rock mines. While typical stoping mines may also have voids filled with broken rock, these are much smaller in scale, so typical seismic waves generated by mine microseismicity, with wavelengths in the range of 3-300 m, can pass through neighbouring pillars without much effect. In contrast, cave mine voids are commonly orders of magnitude larger and are at least a few hundred metres in scale, surrounded by a fractured zone typically around $50-150 \mathrm{~m}$ thickness.

The size of this fracture zone at Cadia is supported by visual inspections undertaken around openings within the cave zone of influence at the neighbouring Ridgeway caving mine (Lett \& Capes 2012), and agrees with observations at other block cave mines (e.g. Glazer \& Hepworth 2005). This produces significant seismic-ray bending from brittle fractures on one side of the cave to seismic sensors on the other side. Figure 1 shows this effect and compares it to the well-known conceptual model of Duplancic (2001). The zone of loosening (Duplancic model) corresponds to the fracture zone region (Lynch model) that is so highly fractured, and therefore destressed, that microseismic events are not recorded from this region. 


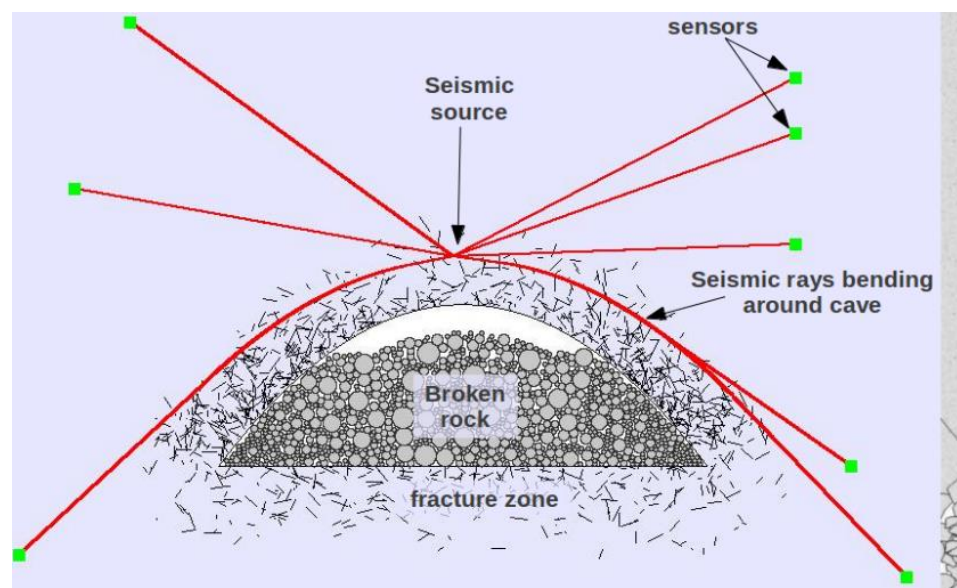

(a)

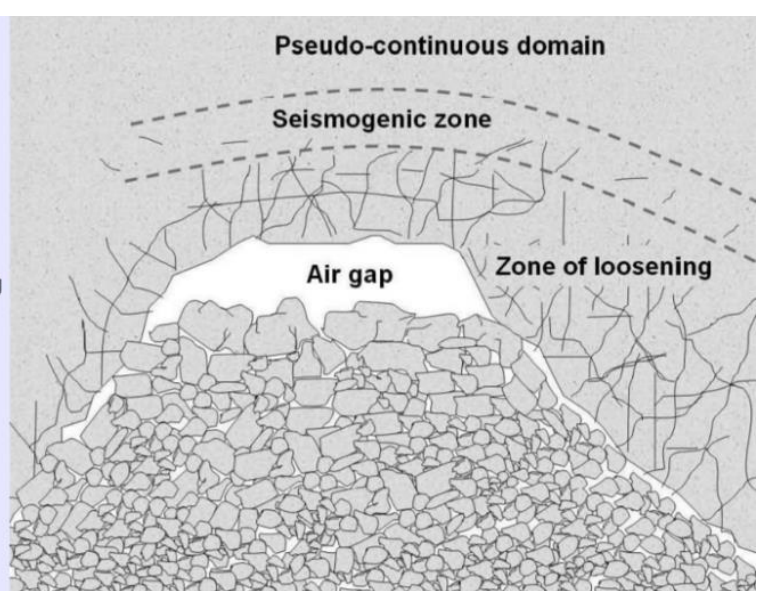

(b)

Figure 1 (a) Indicative schematic showing seismic rays curve around the low-velocity zone of the cave (reproduced from Lynch 2016); and, (b) Conceptual model of caving process and domains (Duplancic 2001)

Microseismic events can be recorded only when the failure or movement of the rock mass radiates sufficient energy at relevant frequencies. The amount of energy required and the frequency range that can be detected depends on the stress drop at the source, capabilities of the monitoring system and background noise levels. As stresses are very low within the fracture zone close to the cave surface, recordable seismicity does not occur there, but rather on the outer edge of the fracture zone (Lynch 2016). Thus, a large portion of the fracture zone will appear to be aseismic, as has been reported by Duplancic and Brady (1999) and Glazer and Hepworth (2005), among others. This critical region between the seismogenic zone and airgap or muck pile is called the aseismic gap, and is unfortunately site-specific as it is dependent on the virgin stress state, physical rock properties, technical characteristics of the microseismic recording system, etc. Typically, the aseismic gap is in the range $50-150 \mathrm{~m}$ for an underground hard rock caving mine. Seismic body wave velocities decrease from $100 \%$ in the solid to $80-90 \%$ just outside the cave surface. Within the cave itself, the muck pile of broken rock has rather low ( $10 \%)$ seismic velocities, with very high inelastic attenuation. This conceptual model and description model are not only supported by experience and observations (Duplancic \& Brady 1999; Glazer \& Hepworth 2005), but also through physical models of the caving process (Cumming-Potvin et al. 2016).

\section{Seismic event locations}

As a cave grows and propagates, the failure of the rock mass ahead of the cave back generates seismicity. Locating and tracking this seismicity can, therefore, be used to infer the location of the cave. However, the estimations of the cave position cannot be expected to be extremely accurate due to the aseismic gap, which, as stated, is site-specific and not constant at a particular site, as well as other factors such as location accuracy and system sensitivity. For a specific time period (e.g. a week), the recorded microseismic events locating above the cave back give some indication as to where the cave is. As the cave grows, the events will also migrate upwards, allowing one to track the cave growth. For example, if the cluster of events above the cave moves up $60 \mathrm{~m}$ in one month, one can say that the cave was growing at approximately $2 \mathrm{~m}$ per day, on average. However, this assumes that event locations are accurate (or that at least accuracy remained consistent) and that the size of the aseismic gap also remained constant. If the cluster of microseismic events disappears and this is not attributed to problems with the system, the most likely explanation is that the cave has stalled. This idea of microseismic event locations migrating over time as the cave grows is shown in Figure 2, taken from the Cadia East PC1 cave. For any time period, the location of the cave could be guessed from the event locations at that time. 
Event Time

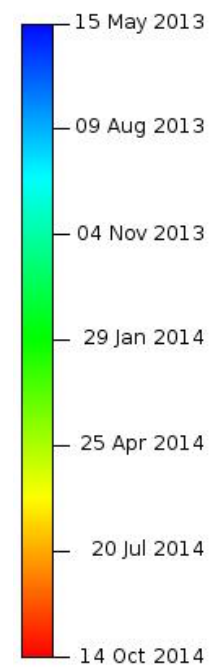

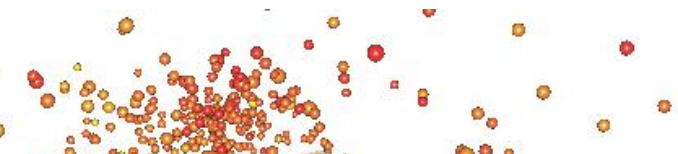

क 8 के
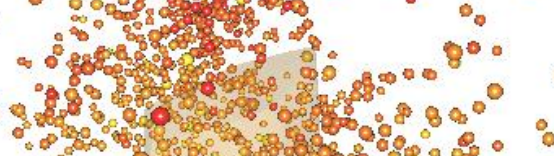

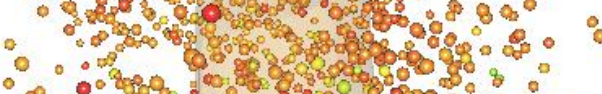

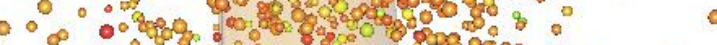

$\infty$

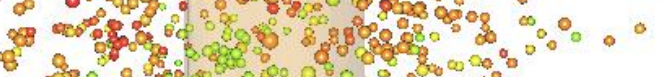

$0^{\infty}$
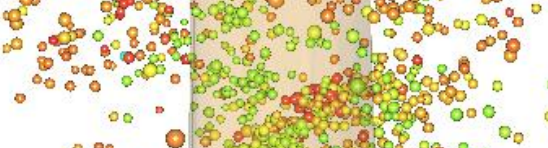

$\circ$
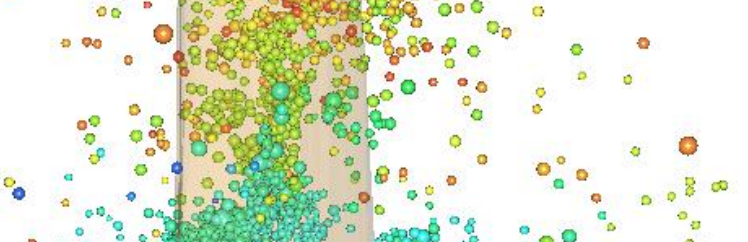

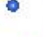
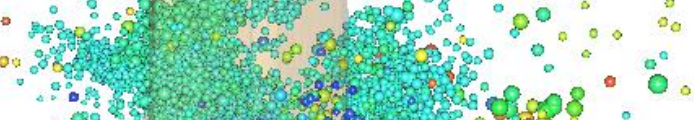

cos o

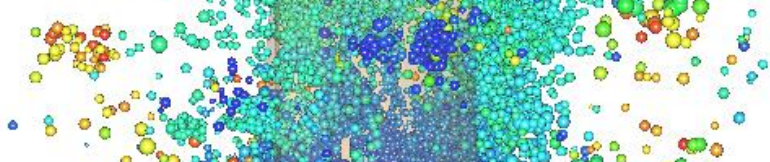

$\cdot$
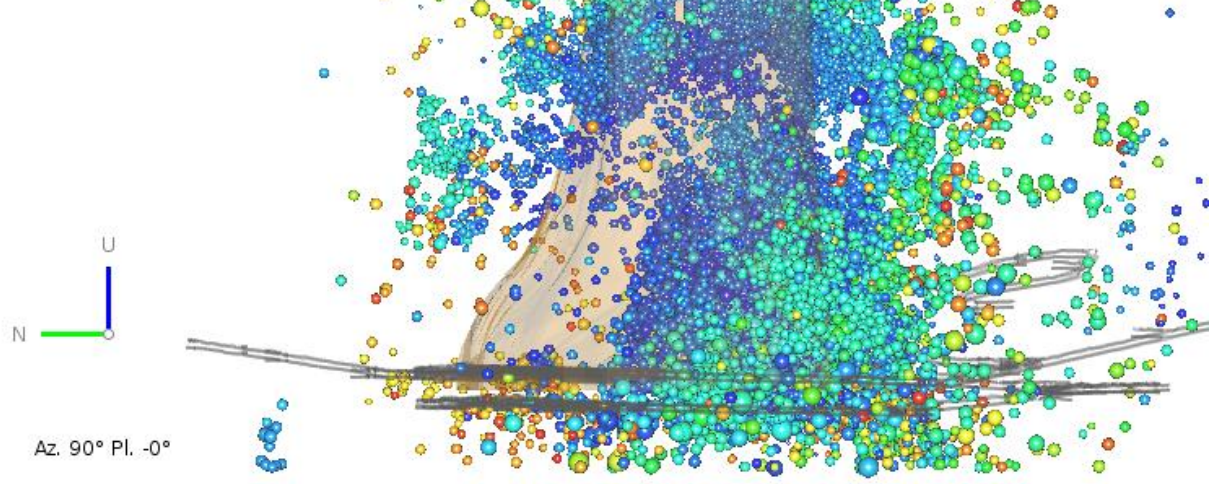

Az. $90^{\circ} \mathrm{Pl},-0^{\circ}$

Figure 2 Illustration the vertical propagation of microseismic events over time, from the PC1 cave at Cadia East mine, Australia

This method is simple and generally effective, but it can be non-trivial to reliably determine a cave surface beneath the cloud of microseismic events. Harder rock units will produce more seismic events, so inhomogeneities can complicate the analysis. Microseismicity due to the caving process must be separated from microseismicity due to structures and faults activated by the changing stresses, or else it can distort any cave back estimation. To do this, event locations are used along with source mechanisms. For example, if a number of events are located in a planar configuration and one of the conjugate moment tensor planes has the same orientation for each of the events, we can confidently attribute those events to slip on a fault rather than the advancing cave front. Figure 3 shows an example of this problem from the PC2 caving operation at Cadia East mine, Australia. The potential cave shape interpretation can vary significantly depending on which events are assumed to be associated with the fracture zone. Including the cluster of events to the east will result in a larger, wider cave shape (red dashed contour) than if they are excluded (blue dashed contour). 


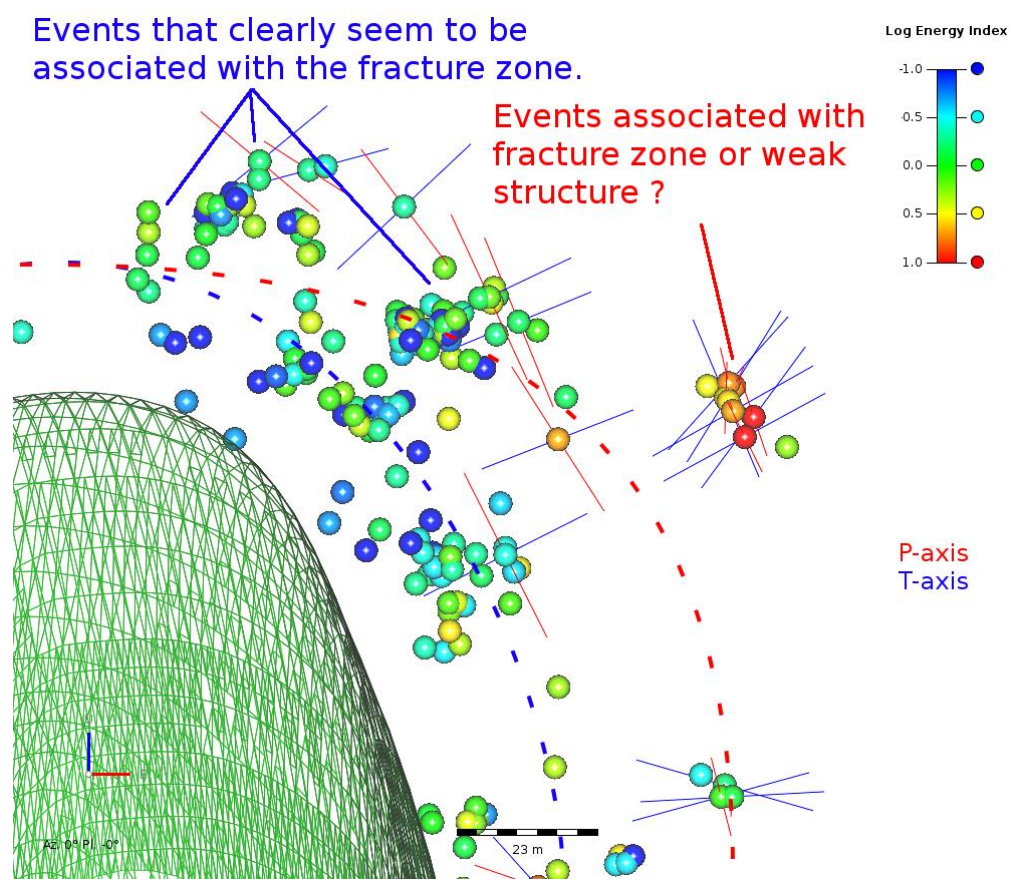

Figure 3 Illustration of the importance of accurate interpretation of seismicity, from the PC2 cave at Cadia East mine, Australia

One problem with event locations is that they do not provide information on the relative position of the cave at the time of the event. Seismicity associated with cave growth is mostly expected to occur above the crown, but it can also occur on the sides and shoulders of the cave. Looking only at the locations of events, it is not always apparent what the orientation of the cave boundary is relative to the events in question. By analysing the seismic source mechanisms, however, it can provide a much better idea of where the events in question are relative to the nearest part of the cave.

\section{$4 \quad$ Seismic event source mechanisms}

The orientation of the fractures occurring in the seismogenic zone are determined by the local stress conditions, which are generally perturbed by the presence of the cave. It is expected that the maximum principal stress, $\sigma_{1}$, will be parallel to the nearest surface of the cave, while minimum principal stress, $\sigma_{3}$, will be orthogonal to the nearest surface of the cave. Therefore, the measured $\mathrm{P}$ - and T-axes from seismic source mechanisms, which are proxies of $\sigma_{1}$ and $\sigma_{3}$, respectively, should also be tangential and orthogonal to the nearest part of the cave.

Furthermore, the analysis of seismic source mechanisms can help differentiate events associated with nearby weak geological structures activated by changing stress conditions from those associated with fracturing in the seismogenic zone. The association of microseismic events to appropriate source processes is vital in the accurate interpretation of seismicity associated with a growing cave.

The analysis of seismic source mechanisms also provides another method of quantifying the agreement between the assumed cave shape and observed data. A boundary element method static stress model of the mine is constructed, using the cave shape assumed at a certain time. The shear and normal stresses on the nodal planes of the seismic source mechanisms are calculated and mapped to a Mohr diagram. The shape of the cave is then updated and a stress model calculated using the new cave shape. The Mohr diagram is then updated based on the new shear and normal stresses. This concept is illustrated in Figure 4. The top-left image shows the observed seismicity, original cave shape (red dashed curve) and expected $\sigma_{1}$ curves, with associated Mohr diagram at the top-right. The model is then updated using available data (lower-left) and the Mohr diagram updated, accounting for the new cave shape (blue) and introduction of a weak geological weakness (green). 

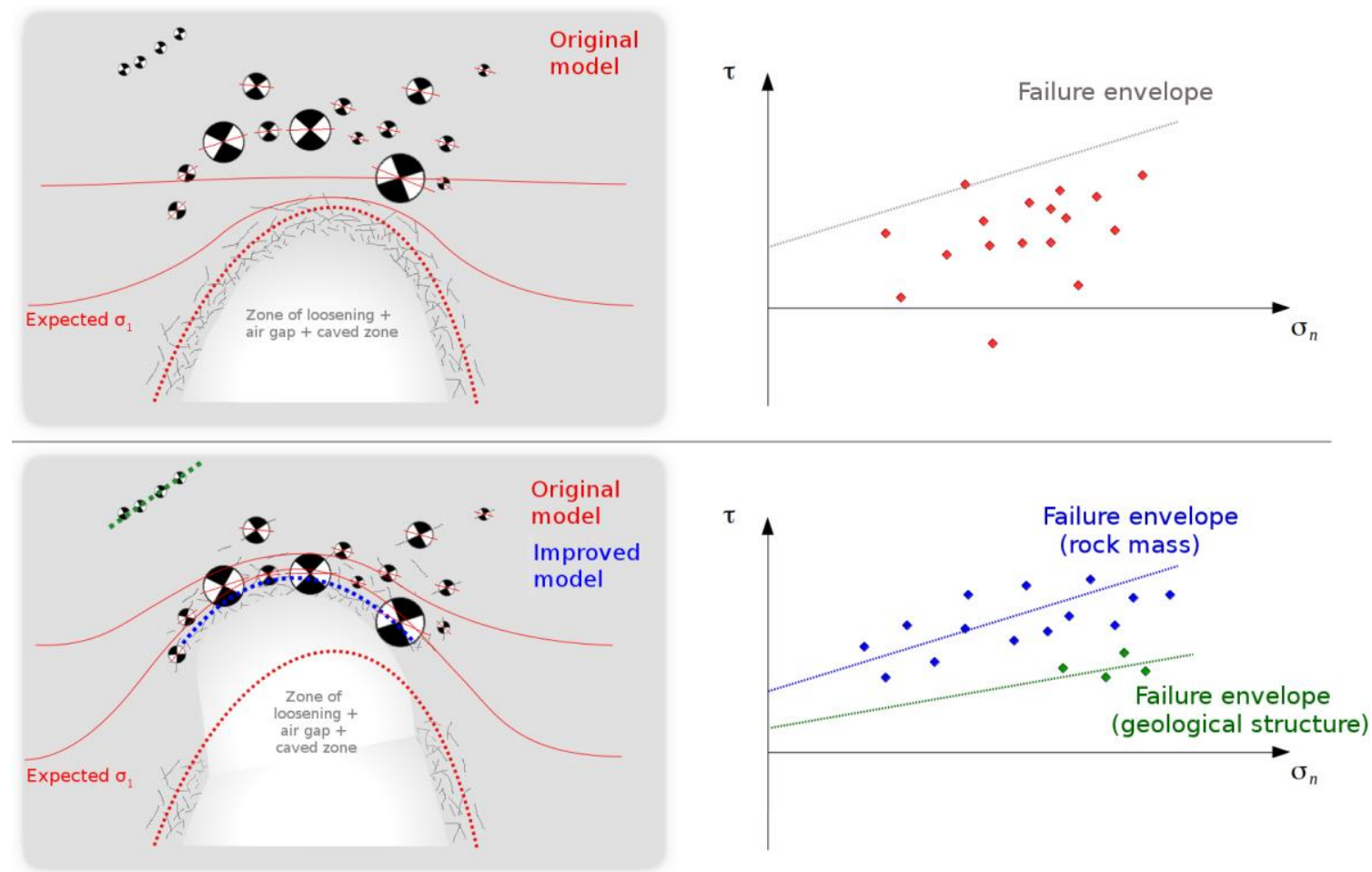

Figure 4 Illustration of the concept of updating the cave shape and mapping of nodal planes to a Mohr diagram. The updated stresses are more consistent with failure on the observed nodal planes. $\mathrm{P}$-axes of events (small red lines through beach balls) are expected to be close to parallel to $\sigma_{1}$ (image courtesy of D Malovichko)

The orientation of the principal axes of seismic source mechanisms, particularly the P-axes, can provide good insight into the state of the cave. In undisturbed conditions, the P-axes should have a very similar orientation to local virgin $\sigma_{1}$. Any significant deviation from this is indicative of a major disturbance of the stress field as was illustrated in the illustration example in Figure 4, and real data in Figure 5. The possible shape of the cave inferred from the expected trajectory of $\sigma_{1}$ based on seismic source mechanisms is compared to shapes estimated by the mine. At lower depths, $Z=4750-4800$ and $Z=4800-4850$, the agreement is quite good. However, higher up and closer to the crown of the cave, the orientation of the $P$-axes indicates that the trajectory of $\sigma_{1}$ is more consistent with the cave being slightly further to the north than currently estimated. 

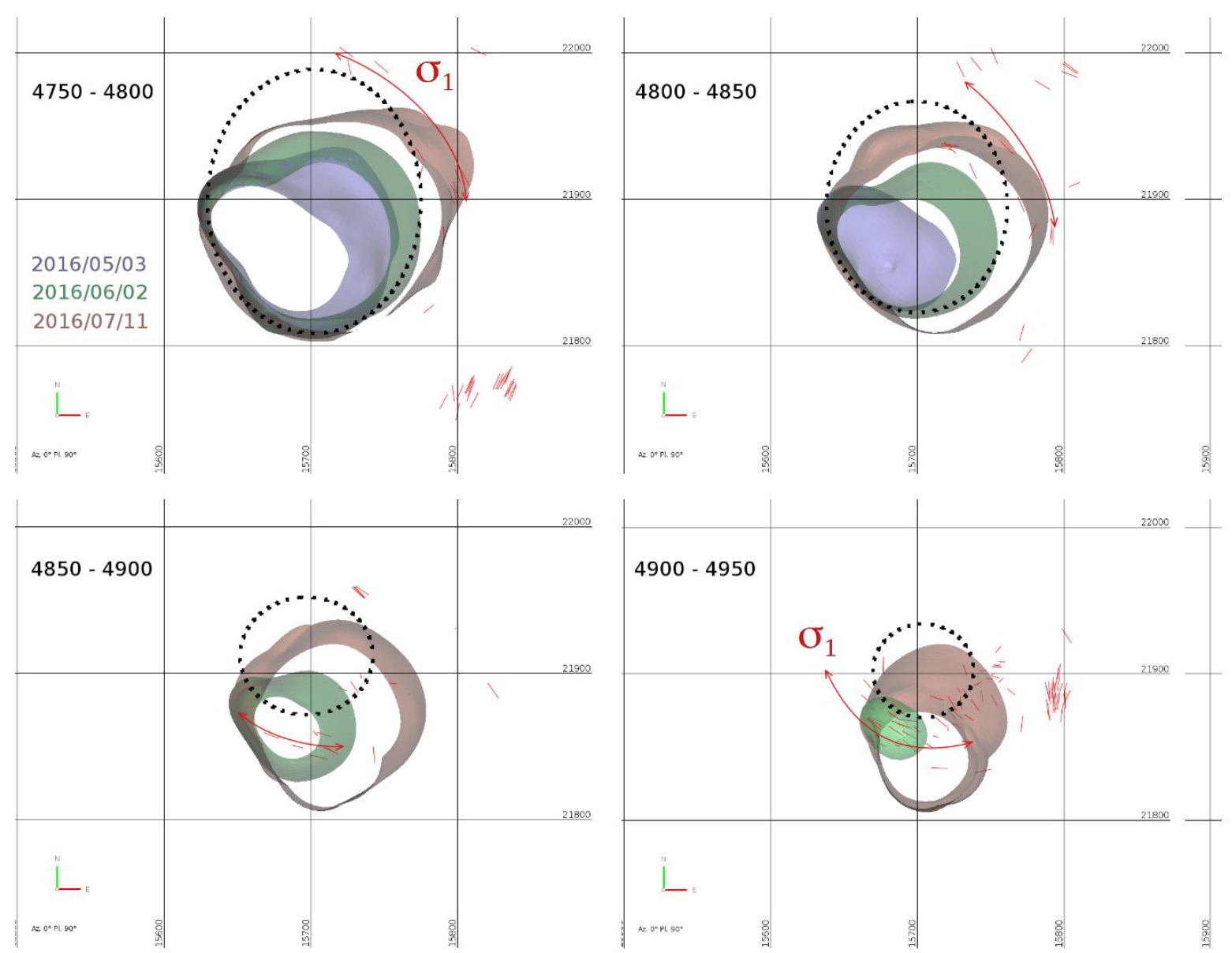

Figure 5 Comparison of cave shapes estimated by the mine at three different periods for four different $50 \mathrm{~m}$ vertical sections. Source mechanisms for events are shown as short, red lines representing their P-axes (proxy of $\sigma_{1}$ ). The trajectory of $\sigma_{1}$ extrapolated from the orientation of the P-axes is shown as the red, bent vectors. The black, dotted lines represent possible cave positions based on these interpolated $\sigma_{1}$ trajectories. Undisturbed $\sigma_{1}$ is approximately east-northeast-west-southwest (image courtesy of D Malovichko)

\section{$5 \quad$ Anomalous travel times}

As illustrated in Figure 1, some seismic ray paths from source to sensor bend around the cave. If a straight-ray homogeneous seismic velocity model is being used for the location of seismic events, the curved ray sensors would be discarded during processing as the observed arrival times would be too different (delayed) from what is expected. In this way, the seismic event locations, obtained with only the straight-ray sensors and a straight-ray homogeneous velocity model, are reliable. However, these curved rays contain information about the cave geometry. Being able to plot these curved rays in 3D, for different time periods, would illuminate where the cave is, and how it is growing in time.

To plot these curved rays in 3D, informally called 'spaghetti', the following simple procedure is followed:

1. For each located seismic event, for each seismogram and for each body wave, measure the difference, $\delta$ t, between the observed arrival time and the expected arrival time under the straight-ray assumption.

2. Convert travel time difference $\delta \mathrm{t}$ to a path-length increase $\delta \mathrm{L}$ by using the solid-rock homogeneous seismic velocity for that type of body wave: $\delta \mathrm{L}=\mathrm{v} \delta \mathrm{t}$.

3. Obtain the radius of a circle passing through source and sensor with arc length $L+\delta L$, where $L$ is the straight-ray source-sensor distance. 
4. Create an arc in 3D by bending the source-sensor line away from the closest point on the current 'best guess' cave surface.

5. The spaghetti curves can be visualised in 3D to illustrate the amount of bending experienced by seismic waves.

Figure 6 provides an example of some seismogram data used to generate these spaghetti curves. The observed seismograms are vertically ordered in hypocentral distance from the source. The observed (picked) $\mathrm{P}$ - and S-wave arrival times are shown by the short vertical black lines with corresponding ' $\mathrm{P}$ ' and ' $\mathrm{S}$ ' labels. Expected arrival times are shown by the slanted lines crossing the seismograms. By assuming that the delay in observed arrival time is due to a longer path length, this delay can be translated into an increase in path length (Figure 7).

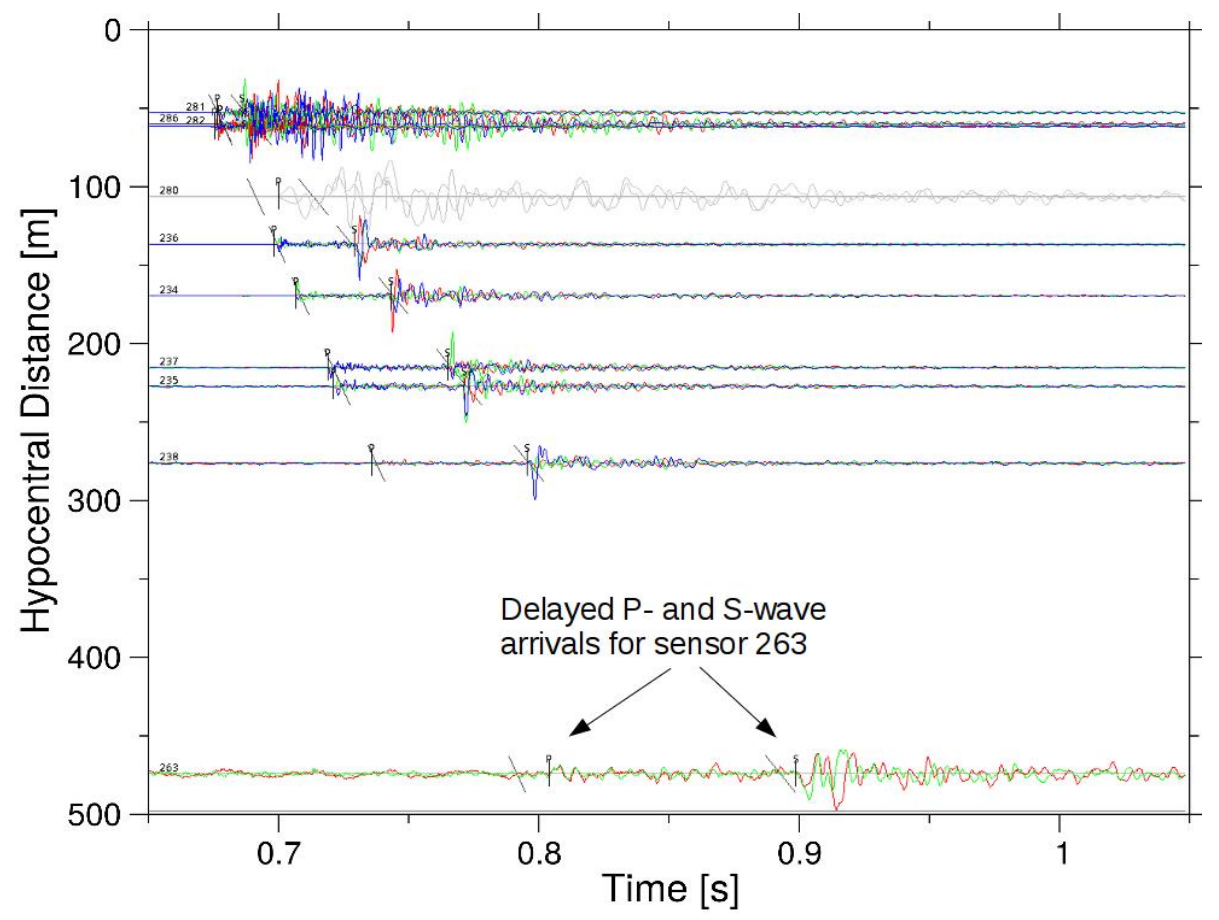

Figure 6 Plot of the seismograms recorded for a seismic event at 00:49:15 on 5 August 2016. Observed arrival times at site 263 (bottom seismogram) are clearly delayed relative to the expected arrival times

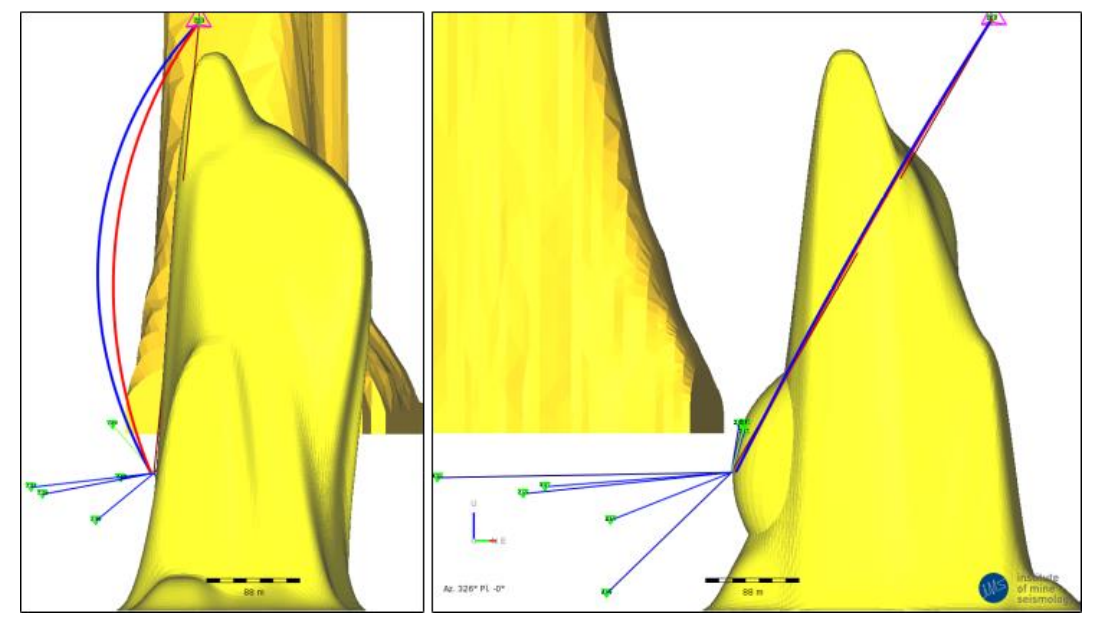

Figure 7 Two section views of the PC1 and PC2 cave shapes for early August 2016 interpreted from open hole, production and seismic data with the seismic event located at the vertex of the lines. The spaghetti curved ray for the P-wave and S-wave is shown by the bold blue and red curved lines. 


\section{Validation}

These aspects of the microseismic data - event locations, source mechanisms and anomalous travel times are used to make a regular estimate of the 3D cave shape for the PC2 cave at Cadia East mine, which is provided to mine geotechnical engineers. The geotechnical engineers also make use of open holes to determine where the cave surface is. This method is practically difficult, as drilling through the fractured zone is time consuming and sometimes unsuccessful. At Cadia East, the drill bits are sometimes clamped in the hole by the fractured dislocating rock. Nonetheless, if a hole is successfully drilled through to the cave surface, we have a high-reliability measurement of where the cave surface is at that 3D position and at that time.

In early 2017, an open hole was successfully drilled through to the PC2 cave surface near the top of the cave. At the time, there were two estimates for the cave surface. One is estimated shape derived from microseismic data as discussed previously - seismic event locations, source mechanisms and anomalous travel times. The other shape was estimated from a combination of previous open borehole observations and production data.

The open borehole data showed that both estimates were too high at that position. However, the microseismic data derived shape was closer to the true height with only a $6 \mathrm{~m}$ error, compared with a $40 \mathrm{~m}$ error for the cave shape estimated by the mine using non-seismic data (Figure 8).
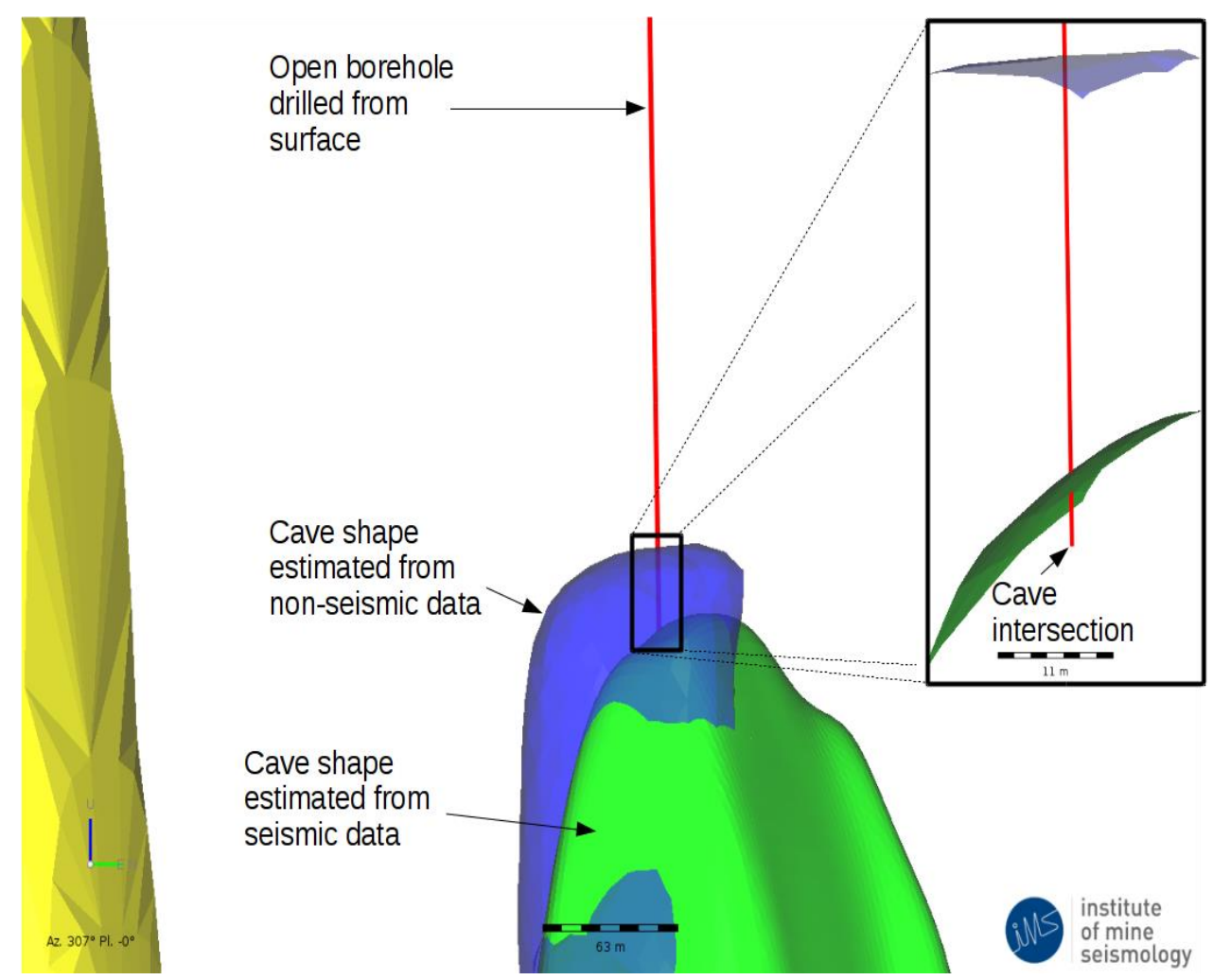

Figure 8 Section view of the PC1 cave shape (yellow) with the two estimated cave shapes for PC2 in early 2017; from seismic data (green) and from non-seismic data (blue). The open borehole drilled from surface (red line) intersecting the cave shows that the green cave shape was more accurate

\section{Conclusion}

While seismic event locations above a growing cave are useful to give indications of the cave growth, care should be taken to first remove microseismicity associated with weak structures and faults around the cave. As many seismic source mechanisms as possible should be calculated, as this data can be used in two manners to give indications of the cave geometry. Firstly, the $\mathrm{P}$ - and T-axes of the mechanisms can be taken as proxies for the principal major and minor stresses, and thus yield information about the orientation of the closest cave surface. Secondly, the static stresses calculated using a trial cave geometry can be checked against the 
observed fracture slips. Anomalous travel times are observed at sensors most affected by the cave, and can be used to create $3 \mathrm{D}$ curved rays indicating where the cave is and, by repeating the analysis over time, where it is growing.

The different facets of the seismic data are now used routinely to provide estimated cave shapes, which help to better manage the cave mining process. Verification of these shapes, and these analysis techniques, is not easy but the one open-hole verification that has been made suggests the indicated cave shapes using these seismic techniques may be accurate.

The work presented in this paper has already been implemented and is currently used routinely in some block caving operations. Research is currently ongoing on the topic of cave front tracking using seismic methods. In future, active seismic sources (e.g. Lynch 2010, 2012; Lynch et al. 2013) and ambient noise methods (e.g. Olivier et al. 2015) are expected to be used routinely to further improve cave front tracking.

\section{Acknowledgement}

The authors acknowledge the support of Newcrest Mining Limited, one of the patrons of the Institute of Mine Seismology. In particular, the support and encouragement of David Cuello, Andrea Jaeger, Eamonn Hancock and Chris Chester is appreciated.

\section{References}

Cumming-Potvin, D, Wesseloo, J, Jacobsz, SW \& Kearsley, E 2016, 'Results from physical models of block caving', Proceedings of MassMin 2016, The Australasian Institute of Mining and Metallurgy, Melbourne, pp. 329-340.

Duplancic, P \& Brady, BH 1999, 'Characterisation of caving mechanisms by analysis of seismicity and rock stress', in G Vouille \& P Berest (eds), Proceedings of Ninth Congress International Society for Rock Mechanics, vol. 2, A.A. Balkema, Rotterdam, pp. 1049-1053

Duplancic, P 2001, Characterisation of Caving Mechanisms Through Analysis of Stress and Seismicity, PhD thesis, The University of Western Australia.

Glazer, SN \& Hepworth, N 2005, 'Seismicity induced by cave mining, Palabora experience', in Y Potvin \& M Hudyma (eds), Proceedings of the Sixth International Symposium on Rockbursts and Seismicity in Mines, Australian Centre for Geomechanics, Perth, pp. 281-290.

Lett, JL \& Capes, GW 2012, 'Characterisation of caving and subsidence for operational enhancements at the Newcrest Ridgeway Gold Mine', Proceedings of MassMin 2012, Canadian Institute of Mining, Metallurgy and Petroleum, Westmount.

Lett, JL, Brunton I, Capes, GW, Jäger, A, Mobilio, B, Rachocki, J, Sharrock, GB \& Secheny, M 2016, 'Undercutting to surface breakthrough - Cadia East panel cave (stage 1)', Proceedings of MassMin 2016, The Australasian Institute of Mining and Metallurgy, Melbourne, pp. 65-81.

Lynch, RA 2010, Keynote Address: Passive and Active Microseismic Monitoring in Mines, presented at the Fifth International Seminar on Deep and High Stress Mining, hosted by the Australian Centre for Geomechanics.

Lynch, RA 2012, 'Active seismic monitoring', in Y Potvin (ed.), Proceedings of the Sixth International Seminar on Deep and High Stress Mining, Australian Centre for Geomechanics, Perth, pp. 201-210.

Lynch, RA 2016, 'Active and passive seismic monitoring of cave front evolution', Proceedings of MassMin 2016, The Australasian Institute of Mining and Metallurgy, Melbourne, pp. 217-224.

Lynch, RA, Olivier, G \& Green, MT 2013, 'High accuracy measurements of seismic velocity variations in mines', in A Malovichko \& D Malovichko (eds), Proceedings of the Eighth International Symposium on Rockbursts and Seismicity in Mines, GS RAS \& MI UB RAS, Obninsk-Perm, pp. 157-165.

Mendecki, AJ 1997, Seismic Monitoring of Mines, Chapman-Hall, London.

Mercier, JP, de Beer, W, Mercier, JP \& Morris, S 2015, 'Evolution of a block cave from time-lapse passive source body-wave traveltime tomography', Geophysics, vol. 80, no. 2, pp. WA85-WA97.

Olivier, G, Brenguier, F, Campillo, M, Lynch, RA \& Roux, P 2015, 'Body-wave reconstruction from ambient seismic noise correlations in an underground mine', Geophysics, vol. 80, no. 3, pp. 1-15.

Westman, E, Luxbacher, K \& Schafrik, S 2012, 'Passive seismic tomography for three-dimensional time-lapse imaging of mininginduced rock mass changes', The Leading Edge, vol. 31, no. 3, pp. 338-345. 